\title{
Marx y Laclau. Retomar la política desde el enfoque discursivo
}

Ricardo Padilla Rizo

Universidad Autónoma de Aguascalientes ricardo.padilla@live.com.mx

\section{Introducción}

El presente trabajo tiene el propósito de repensar el alcance de la práctica política, pero desde un enfoque discursivo. El problema es interpretar algunas ideas del marxismo a partir de un marco teórico contemporáneo: la teoría del discurso de Ernesto Laclau. Tres cuestiones son las que figuran a lo largo del escrito: ¿qué es la sociedad?, en referencia a su comprensión ontológica y que discute la relación entre la idea de discurso y el materialismo de Marx; ¿cómo se organiza el pueblo contra el bloque de poder?, desde estos conceptos se reflexiona sobre la estrategia de la sociedad inconforme para resistir al poder; y, ¿qué es la representación política?, que hace alusión al concepto de representación hegemónica y el papel del partido en la teoría política clásica. Estos son problemas planteados en la teoría política tradicionalmente. El enfoque discursivo que tomamos de Ernesto Laclau sirve 
para refrescar el problema y su respuesta. El escrito lo organicé en tres partes: la primera es la exposición de la teoría de Laclau. En la segunda, retomo algunos pasajes de Marx para considerar que es pertinente la vuelta a la lectura del autor moderno, aunque con matices en la manera de abordarlo. Y en la tercera y a modo de conclusión, planteo que el éxito de la lucha contra el neoliberalismo depende en parte de prácticas individuales que realicen valores humanos.

\section{Teoría del discurso}

Crisis del marxismo. Los primeros escritos de Laclau en los años setenta se encontraron en medio de una circunstancia particular: la del desencanto y la decepción por la ideología marxista frente al auge del neoliberalismo y del llamado fracaso de los socialismos reales. Sus críticas iniciales se dirigieron hacia lecturas economicistas del marxismo realizadas por otros marxistas. Este economicismo se manifestaba en reduccionismos de clase de las luchas políticas, o en la abstracción de la economía respecto de la política como esferas autónomas de la realidad. La respuesta fuerte de Laclau la formuló con Chantal Mouffe en Hegemonía y estrategia socialista, en 1985, con el nombre de posmarxismo. Ahí sostenían un enfoque discursivo para discutir tanto la ontología materialista del marxismo como la epistemología realista de la sociología y de la ciencia política. De tal modo que la realidad es un discurso y su conocimiento no es objetivo, en el sentido clásico.

Discurso y sociedad. ¿Qué es la sociedad? Esta pregunta es el punto de partida ontológico y epistemológico del posmarxismo para rebatir el dogma materialista y su fuente es Saussure. Menciono tan sólo dos ideas relevantes para Laclau: la 
primera es el principio de relacionalidad (Laclau y Mouffe, 2004: 144). Según este principio, el significado de un signo está determinado por su relación con signos contiguos. Así que ningún signo tiene un significado a priori; la segunda es el principio de arbitrariedad, que se refiere al carácter arbitrario del nacimiento del vínculo entre significante y significado. La palabra y el concepto se vinculan arbitrariamente. Una vez que se da un vínculo, éste debe sostenerse para dar cierta estabilidad a la lengua, de otro modo no sería posible la comunicación. Esto implica la posibilidad de que un signo adquiera un significado nuevo si se establecen nuevas relaciones con otros signos.

El esquema de Saussure es utilizado por Laclau como base para explicar la constitución de la sociedad. Al igual que el lenguaje, la sociedad es un concepto abstracto, cuya estabilidad depende de la repetición de los significantes que le dan forma en el plano de lo concreto. El avance de Laclau consiste en comprender el discurso como algo que abarca y excede la esfera lingüística. No distingue entre lo lingüístico y lo no lingüístico, las prácticas sociales constituyen formas de discurso porque expresan significados y dan significado a otras prácticas (Laclau, 2007). Por ello, la estabilidad de un orden social depende de la estabilidad de las prácticas discursivas, de la reproducción de la ideología, diría Althusser (2010). La sociedad requiere la definición temporal y contingente de ciertos elementos que den cohesión y generen un tipo de orden. Los elementos discursivos que dan estabilidad a una sociedad los llama Laclau «puntos nodales» (Laclau y Mouffe, 2004: 152). Estos son símbolos y prácticas que se van sedimentando con el tiempo para dar forma a una sociedad.

Pero el problema que se desprende es que la sociedad es imposible (Laclau, 2000). «Sociedad» no es un objeto sino 
una construcción discursiva, contingente y siempre susceptible de ser transformada. Así, los puntos nodales que constituyen un discurso surgen como un infinito intento de fijar la forma de orden social, siempre de forma contingente y temporal. Como consecuencia de este enfoque, la jerarquización a priori de elementos que configuran lo social, como la economía en el marxismo, pierde sentido. Como dice Laclau:

En nuestra perspectiva no existe un más allá del juego de las diferencias, ningún fundamento que privilegia a priori algunos elementos del todo por encima de los otros. Cualquiera que sea la centralidad adquirida por un elemento, debe ser explicada por el juego de las diferencias como tal (2011: 93).

De este modo se descarta la conocida sentencia de «la economía determinante en última instancia». Para Laclau, la economía no es un campo aislado y objetivo del discurso social, sino un elemento indecidible, es decir, cuyos límites con la política, la cultura, la historia, etcétera, no pueden trazarse objetivamente. La separación de lo económico es resultado de una abstracción, de un trabajo intelectual que divide conceptos. Este enfoque discursivo afecta de la misma manera la construcción de las identidades sociales. Éstas no pueden reducirse a posiciones objetivas de clase, como determinaciones económicas. Las identidades sociales son, al igual que los signos, producto de las relaciones con otras identidades, signos, prácticas, etcétera. Laclau entiende el concepto de sujeto de esta manera:

Siempre que en este texto utilicemos la categoría de «sujeto», lo haremos en el sentido de posiciones de 
sujeto en el interior de una estructura discursiva. Por tanto, los sujetos no pueden ser el origen de las relaciones sociales, ni siquiera en el sentido limitado de estar dotados de facultades que posibiliten una experiencia, ya que toda experiencia depende de condiciones discursivas de posibilidades precisas (Laclau y Mouffe, 2004: 156).

Aquí radica el rechazo del esencialismo moderno. En ningún momento la identidad del sujeto podría fijarse para siempre. Y lo mismo puede extenderse hacia las ideas de Estado y de sociedad civil. En síntesis, la sociedad es el producto siempre inacabado de articulaciones y desarticulaciones de elementos discursivos. Algunos de ellos quedan sedimentados para configurar un orden social estable, pero ello siempre es temporal y contingente.

Discurso y hegemonía. El conjunto de este proceso de articulación y desarticulación de elementos discursivos, de la instauración de puntos nodales y de una forma particular de orden social es la hegemonía, que en la primera formulación de Laclau es asimilable a la política (Laclau y Mouffe, 2004). Hegemonía no es sólo la relación vertical del bloque de poder sobre el pueblo, son luchas hegemónicas tanto las que buscan modificar como conservar el discurso dominante. La simplificación que señalaba Marx respecto a las clases proletaria y burguesa en la sociedad capitalista, es reformulada como un antagonismo radical entre dos identidades, pero de acuerdo con Laclau, entre ellas no hay o no debería haber a priori definiciones clasistas. La división política la expresa Laclau al estilo de Gramsci, como pueblo y bloque de poder, pero el contenido ideológico de cada parte no puede ser 
anticipado y depende de la identidad que se construya. Lo que agrega el concepto de antagonismo es que considera las identidades políticas como algo inacabado. Las identidades antagónicas, al ser también productos del discurso, no son constantes, dependen de las demandas que están en juego.

Otro aspecto de la política como hegemonía es la formación de cadenas de equivalencia, lo cual responde a la pregunta de cómo se organiza el pueblo contra el bloque de poder. El antagonismo social no es uno, pero la simplificación que tiene como objetivo la lucha contra el poder dominante requiere de una organización de las fracciones sociales, de las diferentes identidades frente al bloque de poder. Dicha organización consiste en la articulación en el plano horizontal de las demandas particulares para crear una cadena equivalencial lo suficientemente extensa para desarticular la hegemónica. Al final, se trata de una lucha formal por el poder, en el sentido de que los contenidos ideológicos de las luchas no son necesarios, aunque la idea de la articulación conviene de cierta manera a la idea de democracia.

Existe una ambigüedad en esta formulación porque por un lado la cadena de equivalencia parece expresar un peso cuantitativo si depende de su extensión, pero en realidad se refiere a un rasgo cualitativo. La organización más fuerte sería aquella capaz de incluir mayor diversidad de demandas. Es por ello que la articulación no es de individuos, sino de demandas y de significados.

Populismo y demanda popular. La razón populista propone una reformulación de la política que complementa la de hegemonía. El populismo parte de la demanda como unidad de análisis. En lugar de elementos discursivos, «demanda» expresa un carácter performativo en el sentido de que se 
reclama algo al bloque de poder. La demanda es la materia concreta de las cadenas de equivalencia y que unificadas conformarían la identidad del pueblo. Particularmente las demandas con más fuerza política son las que permanecen insatisfechas, porque se mantienen vivas en el campo de la lucha hegemónica, a diferencia de las demandas satisfechas que terminan anulando su poder de confrontación al ser absorbidas por el sistema. Es decir, mientras la demanda quede insatisfecha, su capacidad de oponerse al sistema articulándose con otras demandas se mantiene vigente y en ese sentido son demandas populares.

La condición para la articulación de las demandas populares reside en que estén dirigidas al mismo receptor, y para ello se da un doble proceso de construcción de identidades: por un lado la identidad del pueblo, y por otro lado la identidad del adversario o antagónico. Tal relación constituye el antagonismo social que está presente en todas las sociedades, pero no es estable, las demandas articuladas pueden desarticularse, debilitando la cadena equivalencial y fortaleciendo el bloque de poder, o viceversa. Todo depende de la conveniencia de la demanda particular para el conjunto, el objetivo es siempre la unificación del pueblo aunque ésta sea imposible.

De acuerdo con esto, Laclau distingue entre populus y plebs. El populus haría referencia a un pueblo definido cuantitativamente por la mayoría o algo menos que la totalidad, mientras que la plebs es un pueblo cualitativo, puede construirse un pueblo con menos que la mayoría pero con una identidad mejor definida y presentarse como oposición al bloque de poder.

«Pueblo» funciona como un significante, un nombre que unifica la diversidad de demandas. Como el contenido del 
nombre no tiene un referente preciso es un significante vacío. Los sujetos que se identifican con el pueblo (plebs) tienen un lugar de enunciación particular que no puede ser homogeneizado. Cada posición de sujeto ve en el pueblo su propia forma de interpelación. Así que el vacío del significante no significa ausencia, sino una multiplicidad de significados reales y simultáneos.

La mera construcción del pueblo no es suficiente para la lucha hegemónica, requiere de un representante concreto que establezca el diálogo con el pueblo. A diferencia de la representación clásica, que Laclau entiende como la relación unilateral y transparente entre el representante y el representado, como la del partido como el poseedor del saber, la representación hegemónica comprende una inevitable doble relación entre ambas partes. La unificación de las demandas no anula sus diferencias y al mismo tiempo el representante no es sólo un partido o un individuo, sino un sujeto complejo, producto de las proyecciones afectivas del pueblo. A este fenómeno lo llama Laclau «investidura radical» (2011: 142). Al mismo tiempo, la respuesta del líder como escucha del pueblo afecta y fortalece la identidad del pueblo. Tal investidura es la encarnación de una carga semántica de insatisfacción con el orden vigente y no implica necesariamente un proyecto político sustituto.

Lo importante de la formulación populista de la política radica en estos tres aspectos: la articulación, la representación y la unificación de las demandas. Si logra realizarse el momento de la unificación, también se habrá generado una exclusión de lo que no es aceptado por el conjunto del pueblo. Aquello que es excluido tiene un carácter heterogéneo en el sentido que Kuhn hablaba de inconmensurable: 
La heterogeneidad, concebida de esta manera, no significa diferencia; dos entidades, para ser diferentes, necesitan un espacio dentro del cual esa diferencia sea representable, mientras que lo que estamos denominando heterogéneo presupone la ausencia de ese espacio común (Laclau, 2011: 147).

En algunos casos la exclusión y la idea de heterogeneidad son objeto de crítica. El populismo invita a la división de la sociedad y a la formación de un conflicto entre las partes. El problema que esto implica es que el antagonismo social presupone una creencia en la representación política. Y la hay en el enfoque de Laclau, pero no porque sea una creencia racional. El sustento de la creencia en el líder que unifica al pueblo tiene un fundamento pasional, libidinal, de modo que la representación también tiene algo de proyección, de ahí que el vacío del significante «pueblo» sea llenado de diversas maneras según de qué pueblo se habla y esto vincula al populismo con la democracia.

Nuestras preguntas sobre la sociedad, la organización y la representación tienen respuestas generales: el discurso, la articulación y la proyección libidinal. La importancia central que Laclau le concede a la política invita a pensar la política como algo más que una práctica social concreta, es un proceso constitutivo de lo social más allá de lo institucional porque involucra tanto a los sujetos concretos como a la dimensión imaginaria y afectiva.

\section{Releer a Marx}

Discurso y materialismo. Dicho lo anterior, podemos ensayar una lectura de Marx con el enfoque discursivo y populis- 
ta. En primer término, respecto a la ontología de la sociedad se discute el materialismo como una supuesta determinación de las condiciones materiales sobre el pensamiento. Este es el materialismo duro que responde al idealismo y sostiene que las ideas son reflejo de la materia. Pero la postura correcta es la que comprende que la materia no es separable de lo cultural y ambas existen ahí donde el hombre concreto comienza su producción.

Este modo de producción no debe considerarse solamente en cuanto es la reproducción de la existencia física de los individuos. Es ya, más bien un determinado modo de actividad de estos individuos, un determinado modo de manifestar su vida, un determinado modo de vida de los mismos (Marx y Engels, 2011: 12).

La expresión de la vida humana se da mediante el lenguaje y otras prácticas no lingüísticas, eso es el discurso para Laclau. La aportación de Laclau al materialismo de Marx consiste en hacer visible la importancia del lenguaje en la determinación del modo de producción, los motivos rebasan las necesidades biológicas del cuerpo, aunque se originen en éste. En cierto sentido, las necesidades del cuerpo se encuentran demasiado al fondo de la complejidad humana, y lo «humano» se entiende como una condición que no puede disociar una cosa de la otra. En otras palabras, la relación importante de lo cultural y el modo de producción es que la transformación de los esquemas culturales puede generar un cambio en los modos de producción. Por ejemplo, al pensar el propósito del trabajo, de la justificación de la jornada, de la existencia de la riqueza concentrada y principalmente de los valores que promueve el estado de las cosas actual. 
Discurso y praxis. En el mismo sentido, la idea de praxis marxiana debería entenderse como discurso en el siguiente sentido. Toda práctica tiene una intención, algo que expresar, aunque no sea lingüística. La transformación del mundo, como lo sostiene la undécima tesis sobre Feuerbach, comprende una acción humana sensible, que desplaza una actitud pasiva del materialismo determinista, así como la idea del lenguaje como mera expresión. La praxis no sustituye al pensamiento, sino que lo presupone, tal como la idea de discurso al no distinguir entre lo lingüístico y lo no lingüístico.

De ahí que las sentencias deterministas en la concepción de la historia sean discutibles. No podemos negar $\mathrm{u}$ ocultar los pasajes donde es fácil interpretar ese sentido lineal y evolutivo de la historia, de la sucesión de las etapas sociales. Es algo presente en el imaginario de la época moderna. Sin embargo ello no debería considerarse más que como un esquema para explicar algo en términos teóricos.

Por el contrario la idea de praxis y la de historia tienen mucho en común. Es verdad que si Marx sostuvo que la historia ha sido la historia de la lucha de clases y también expresó que la historia la hacen los hombres (2015). Esto porque la producción humana requiere de una voluntad, motivada por las necesidades pero también por la imaginación. La lucha de clases no es inconsciente, se basa en la imposición y lucha de un discurso en el sentido dado aquí. La imposición de significados y prácticas o su rechazo. Más allá del contenido valorativo de los discursos, podríamos decir que al final la lucha por el poder es una lucha entre discursos, donde lo sustancial es el poder.

El poder de la utopía comunista no radica en su configuración como modo de producción, sino como discurso 
alterno al del capitalismo. Considerar el comunismo como el objeto de una voluntad colectiva no tiene que significar literalmente construir una comuna internacional con su sistema económico definido letra por letra, sino que se presenta como el nombre de una promesa de cambio en el orden actual y de una transvaloración:

Las ideas dominantes no son otra cosa que la expresión ideal de las relaciones materiales dominantes, las mismas relaciones dominantes concebidas como ideas; por tanto, las relaciones que hacen de una determinada clase, la clase dominante, son también las que confieren el papel dominante a sus ideas (Marx y Engels, 2011: 48).

Discurso y lucha de clases. De ahí que el problema de la falsa conciencia sea un falso problema. Es un asunto de hegemonía de los discursos. Esto nos conduce al problema de la lucha de clases. Si la consideramos como una relación objetiva, en nuestra circunstancia neoliberal, la lucha revolucionaria se encuentra prácticamente paralizada. El pueblo está despojado de las armas, pero sólo en un sentido. No hay posibilidad de luchar contra un ejército, pero sí mediante las armas del discurso. Si la hegemonía de un discurso radica en la reproducción de los significados dominantes a través de las prácticas de los individuos, la manera de contrarrestar esta hegemonía es mediante el fortalecimiento de un discurso de resistencia, no sólo ideológico sino práctico.

La forma de vida que impone el neoliberalismo puede ser contrarrestada con prácticas individuales o particulares que traten de no ser parte de ese discurso, es decir, prácticas desarticuladas del discurso neoliberal. Esto es, la clase como 
tal tampoco es algo objetivo, la identificación con una va más allá de las relaciones de producción, pero podríamos creer que sí sirve pensar en términos de clase como un recurso metodológico para construir una lucha de clases que parta de las acciones de los que se identifican con la resistencia.

Resumiendo, la alternativa de Laclau a la lucha de clases es la articulación de demandas populares contra un antagónico. El conflicto populista, al rechazar el clasismo como una forma de esencialismo, y además inscrito en una epistemología antirrealista, comprende el antagonismo como una construcción discursiva, no objetiva en el sentido tradicional. Este antagonismo se construye a partir de un límite, el principio de exclusión, que no es objetivo, ni subjetivo, es construido socialmente y es materializado mediante un nombre, o dos, uno para la propia identidad y otro para el «adversario» político. Entonces, ¿cuáles son las prácticas que se requieren para construir una cadena equivalencial antineoliberal?

La respuesta se ubica entre la crítica institucional y la praxis individual. Para Marx la lucha contra el capitalismo no tenía que limitarse a lo nacional. El capitalismo desde sus inicios mostró su dimensión global, como lo llamaba Lenin, imperialista. Sin embargo, ¿no es preciso partir del núcleo del problema? Me refiero al núcleo en la praxis individual. La lucha directa contra el sistema no tiene que ser necesariamente contra los portadores del poder, instituciones y gobierno, pues de esa manera siempre nos encontraremos en desventaja. (Esto a pesar de que eventualmente nos encontramos con casos de destitución de presidentes, bajas en los ratings de televisión, en las ventas de productos, desplomes de multinacionales, etc.) Ni tampoco sería lo más adecuado reaccionar como si existiera en efecto una estructura ideológica determinante. El sujeto concreto siempre tiene la opción 
de decidir ya no con una conciencia de clase, sino con una conciencia moral.

La promesa de la postura populista radica en reconocer las demandas populares como unidades de análisis de la política, es decir, concebir las demandas de los individuos y grupos inconformes como el punto de partida para la acción política, pues ellos son los únicos reales. En la praxis individual esto se lleva a cabo mediante la realización de valores antineoliberales.

De esta manera, utilizar el término «proletariado» como un referente objetivo seguirá trayendo pocos resultados. En cambio, hacer del proletariado un nombre con el cual se identifiquen los inconformes quizás podría traer un resultado más positivo en tanto que no designe posiciones objetivas ni determine la forma de actuar, sino más bien una idea de lo que es posible fuera del neoliberalismo y realizarlo de acuerdo con la perspectiva propia. De acuerdo con esta línea, proletariado es también un significante vacío.

Pero aún no tiene respuesta el problema de la lucha de clase. No es un asunto cuantitativo en el sentido de engrandecer simplemente la cadena, los pobres siempre han sido más, sino que la vía más prometedora es mejorar cualitativamente la lucha mediante la mejora de las prácticas anti-sistema. Por ejemplo, un mayor compromiso con la resistencia al consumismo, a la explotación, con la equidad de género, contra la discriminación, con ciertos valores que ha desplazado la cosmovisión neoliberal.

La alternativa al neoliberalismo no es un literal anti-neoliberalismo, como un bloque cerrado de prácticas y significados, pues habrá sujetos que reprochen algunos aspectos y otros no. Es más, caeríamos en una contradicción lógica que no tiene sentido en el plano concreto, por eso Laclau ma- 
neja el término antagonismo. En este sentido considero que la lucha política de las masas hacia las instituciones corre el riesgo de fracasar y caer en una forma de alienación a la política, algo como un arrebato sin sentido según Žižek (2011). Si el ser humano busca una emancipación debe pensarse en términos concretos, no abstractos. De esta manera la articulación podría tener más éxito si su fuerza recae en la comunión de lo práctico, más que de lo ideológico. Todo esto se resume en un proverbio chino: «antes de iniciar la labor de cambiar al mundo, da tres vueltas por tu propia casa».

Según Laclau, el momento de una revolución no está determinado, surge en el momento de una crisis del orden hegemónico, de la debilitación del poder heurístico de un discurso. En este sentido insisto en que la praxis individual es la vía inicial de un movimiento de resistencia.

¿Emancipación humana o política? La emancipación es un asunto que Marx expuso en sus textos de juventud, Sobre la cuestión judia y Crítica a la filosofía del derecho de Hegel (2015). La emancipación se plantea como la liberación de un poder. La crítica de Marx a Bauer consistía en negar que la eliminación del poder de la Iglesia cristiana sobre los judíos fuera la salida correcta a la alienación al poder del Estado. La salida de Marx es que la verdadera emancipación no es respecto a una Iglesia ni respecto al Estado, ésta es una emancipación institucional. La emancipación real sería humana, no es una demanda política sino una postura filosófica sobre el ser humano.

La política liberal nos invita a abstraernos de la política, de un interés en la comunidad por un interés centrado en el individuo, pero ello no implica ninguna emancipación, más bien una indiferencia a la comprensión de las relaciones de 
poder. La emancipación humana bien podría considerarse un ideal filosófico de Marx, pero que, al igual que la sucesión del capitalismo, puede lograrse a partir de ciertas prácticas antineoliberales. Lo planteo como una pregunta abierta: ¿en qué medida las prácticas políticas de masas o individuales conducen a una enajenación a la misma en tanto que se refuerza el pensamiento sobre el poder y la resistencia estructurales, en lugar de mirar al individuo, sí, pero como productor de su propia libertad?

Así que tenemos dos puntos de enfoque. Uno es la lucha constante contra las relaciones de dominación del sistema; otra es la abstracción relativa del individuo y buscar una libertad en su entorno inmediato, sin que ello signifique una pérdida del sentido comunitario y un énfasis en el individualismo, más bien se trata de suspender un tanto las estrategias teóricas y generar más prácticas en el nivel concreto. Pero para ello hay que establecer una jerarquía de valores humana, no económica.

Sólo cuando el hombre individual real recobra en sí al ciudadano abstracto y se convierte, como hombre individual, en ser genérico, en su trabajo individual y en sus relaciones individuales; sólo cuando el hombre ha reconocido y organizado sus forces propes como fuerzas sociales y cuando, por tanto, no desglosa ya de sí la fuerza bajo la forma de fuerza política, sólo entonces se lleva a cabo la emancipación humana (Marx, 2015: 83).

En este sentido la emancipación humana sería otra forma de significante vacío, pues la emancipación total no puede alcanzarse, puesto que la emancipación es respecto de algo: de la religión, del Estado violento, de la moral, de la economía. 
La emancipación debe definirse respecto al momento actual que vive una sociedad en un momento histórico concreto.

\section{Conclusión. Política en el neoliberalismo}

Recapitulando, de lo dicho lo central es que la dimensión discursiva desplaza en la visión posmarxista el materialismo $\mathrm{y}$ otras formas de esencialismo. En este sentido la idea de revolución puede ser retomada pero no con el mismo sentido. Revolución no puede entenderse ahora como la reconfiguración radical y veloz del orden social, de las relaciones de poder. Este sentido mesiánico de la revolución no tiene sentido en estos días. No obstante es posible pensar en la revolución en otros términos más prudentes.

Las prácticas antineoliberales que cada individuo pueda realizar en su entorno tienen una intencionalidad revolucionaria, pero el sentido del término revolución tiene que matizarse. Revolución no puede ser comprendida como la transformación radical del estado de cosas por dos razones: la primera es que el pueblo está desarmado, por lo tanto, no puede haber una revolución armada. Y segundo, la revolución, como se concibió décadas antes, presuponía una anticipación de la forma de orden que sucedería.

En realidad, nos adherimos más al planteamiento de Arditi cuando sostiene que las insurgencias o movimientos políticos contemporáneos no tienen un plan, sino que ellas mismas son el plan (2012). ¿Qué significa esto? Que considera las protestas contemporáneas como síntoma de una crisis de la legitimidad del sistema hegemónico. Las protestas no tienen plan porque no se puede configurar a priori un estado de cosas que no conocemos, pero sí sabemos que el actual tiene que cambiar, «lo propio de las insurgencias no es di- 
señar un nuevo orden, sino abrir posibilidades mediante un desafío de nuestros imaginarios y mapas cognitivos» (Arditi, 2012: 148).

Así, las protestas no son propiamente la revolución de la lucha de clases, pero sí una forma de resistencia hacia el poder hegemónico. Las protestas, entendidas como participación ciudadana en la crítica y rechazo del orden dominante, requieren al mismo tiempo de un refuerzo en el nivel individual. Puesto que las masas, el pueblo, la sociedad, no existen sino como construcción discursiva de los individuos unidos. De ahí que insista en que la capacidad de cambio de las protestas radica en la convicción del sujeto individual. Aunque no haya un plan mesiánico de las protestas y sean síntomas, para los individuos debe o debería haber al menos una idea vaga de hacia dónde va. Y en este sentido, el hacia dónde va no puede venir de un líder político, sino que tiene que originarse en la conciencia de los individuos bajo una forma moral.

La resistencia hacia el poder hegemónico no puede estar dirigida hacia un sistema, pues, ¿dónde están el sistema, las instituciones, etcétera? Estos son nombres de entidades abstractas, y lo concreto está en el quehacer inmediato de las personas. Es en este sentido que entiendo que las prácticas políticas colectivas pueden caer en una alienación a la política. Para Arditi, las cosas empiezan a ocurrir en la medida que las llevamos a cabo, y las protestas colectivas resultan un fenómeno visible para todos.

El problema, entonces, consiste en esto: ¿las protestas que son nuestra forma actual de la lucha de clase tienen la capacidad de articular a la sociedad lo suficiente para convencer de la pertinencia de valores antineoliberales, las protestas son performativos políticos (Arditi, 2012) que logran que los 
espectadores pasen a ser activistas? En cierto sentido es innegable la necesidad de la resistencia en estos niveles, pero lo que me parece importante es que la construcción del enemigo parte también de una construcción de la propia identidad. De acuerdo con Laclau, la identidad del enemigo y la propia son bicondicionales. Un plan a futuro puede estar ausente, pero no ciertas directrices que no son políticas sino morales.

En síntesis, encontramos dos niveles de la resistencia. El primero es el nivel de lo concreto, basado en la dirección moral y espiritual, ya lo decía Gramsci, anclada en el sujeto que realiza estos valores como virtudes. El segundo es la manifestación colectiva que funciona como performativo político que algo genera en el observador. Quizás éste es el significado fuerte de discurso. No son los meros significados sino las prácticas lo que tiene un poder performativo, de generar la replicación de acciones de resistencia al sistema y no solamente nombrar al enemigo como parte del imaginario.

Finalmente, la práctica antineoliberal podría comenzar con la resistencia crítica a los valores y su jerarquización, a los modelos de vida, formas de expresión cultural, revalorar saberes ancestrales y la crítica al modelo científico. La articulación de las prácticas antineoliberales ha de buscar su representante hegemónico, pero, antes de ello, la creencia en la autonomía de la voluntad sería un paso inicial para la política.

\section{Bibliografía}

Althusser, L. (2010). La filosofía como arma de la revolución. México: Siglo XXI.

Arditi, B. (2012). Las insurgencias no tienen un plan, ellas son el plan: performativos políticos y mediadores evanescentes en 2011. Debate Feminista. 23(46). 146-169. 
Arditi, B. (2009). La política en los bordes del liberalismo. Diferencia, populismo, revolución, emancipación. Argentina: Gedisa.

Borón, A. (2000). Tras el búho de Minerva. Mercado contra democracia en el capitalismo de fin de siglo. Argentina: CLACSO.

Eagleton, T. (2011). Por qué Marx tenía razón. España: Península. Harvey, D. (2007). Breve historia del neoliberalismo. España: Akal.

Laclau, E. (2011). La Razón Populista. Argentina: FCE.

Laclau, E. (2007). Discourse. En Goodin, R. y Pettit, P. (Eds.) The Blackwell Companion to contemporary Political Philosophy. Reino Unido: Blackwell publishing.

Laclau, E. y Mouffe, Ch. (2004). Hegemonía y estrategia socialista. Argentina: FCE.

Laclau, E. (2000). Nuevas reflexiones sobre la revolución de nuestro tiempo. Argentina: Nueva visión.

Laclau, E. (1978). Política e ideología en la teoría marxista: capitalismo, fascismo, populismo. México: Siglo XXI.

Marx, K. (2015). Antología. México: Siglo XXI.

Marx, K. (2011) Introducción general a la crítica de la economía política / 1857. México: Siglo XXI.

Meiksins, E. (1998). Retreat from class. A New «true socialism». Inglaterra: Verso.

Merlin, N. (2015). Populismo y psicoanálisis. Argentina: Letra viva.

Žižek, S. (2011). Ladrones del mundo, uníos. Teknocultura. Revista de Cultura Digital y Movimientos Sociales. 8(2). 207-212. Recuperado de http://teknokultura.net/index.php/tk/article/view/2 


\section{Resumen}

El presente escrito busca exponer los fundamentos teóricos de la teoría del discurso posmarxista, propuesta por Ernesto Laclau, con el propósito de hacer una lectura de algunos textos de Marx en clave discursiva. Primero, se hace un recorrido por los conceptos centrales para esta teoría como discurso, sociedad, hegemonía y populismo. Segundo se aplica la lógica del enfoque discursivo para interpretar los conceptos de materialismo, praxis, lucha de clases y emancipación. Y tercero, se concluye planteando algunas directrices para interpretar el neoliberalismo bajo el mismo enfoque.

Palabras clave: Laclau, Marx, lucha de clases, revolución, ideología, moral.

\section{Abstract}

The present paper exposes the theoretical fundamentals of posmarxist discourse theory, proposed by Ernesto Laclau, this with the aim of make a reading of some Marx's writings under discursive key. First it is made a detour through the main concepts to this theory such as discourse, society, hegemony and populism. In the second part it is applied the logic of discursive view for interpreting marxist concepts such as materialism, praxis, class war and emancipation. Finally, it is concluded posing some guidelines to interpret neoliberalism under same approach.

Key words: Laclau, Marx, Class conflict, revolution, ideology, morals. 
